\title{
Day-to-day variations in body-weight of young women
}

\author{
By MARION F. ROBINSON and PATRICIA E. WATSON \\ Department of Nutrition, School of Home Science, \\ University of Otago, Dunedin, New Zealand
}

\section{(Received 7 September 1964-Accepted I7 November 1964)}

A knowledge of the likely magnitude of day-to-day variations in body-weight is of great value for the interpretation of metabolic balance studies. Durnin ( $\mathrm{rg}$. I) found day-to-day changes of up to $\mathrm{r} \mathrm{kg}$ in a group of forty-four young men living under controlled conditions. The procedure for weighing was highly standardized: 'the men were naked, the measurements were done immediately on their rising from bed in the morning, before any food or drink had been taken, and after the urinary bladder had been emptied.' Edholm (196r) and Adam, Best \& Edholm (196r), following a similar routine, weighed sixty-four soldiers ( $17 \frac{1}{2}-22 \frac{1}{2}$ years) each day for periods of 7 days and of up to 7 weeks. They found, in more than 1700 weighings, a weight change of over $0.5 \mathrm{~kg}$ on $30 \%$ of the occasions, and of over I $\mathrm{kg}$ on $6 \%$. Khosla \& Billewicz (1964), from a study of day-to-day weight changes for from 30 to 40 days in nineteen subjects of varying size, age and sex, showed that the extent of the daily fluctuations of body-weight was related to the body-weight itself, and that the maximum day-to-day change rarely exceeded $\mathrm{I} \cdot 5 \%$ of the body-weight.

The opportunity seldom presents itself to follow adequately the daily weights of a group consisting solely of women. Many workers have reported weight trends with the menstrual cycle, but rarely have the subjects been living in the same environment, been following the same occupation, and been weighed under carefully controlled conditions. The subjects of Klein \& Carey (1957) were hospital personnel and were weighed after breakfast; those of Fortin, Whittkower \& Kalz (1958) were public service employees and were weighed on arrival at work. Body-weights were not always recorded on every consecutive day; some were weighed on work days (Chesley \& Hellman, I957), others on every 2nd day (Fortin et al. I958), or every $3^{\text {rd day }}$ (Danforth, Boyer \& Graff, 1946). Thomas (1953) weighed a group of fourteen women medical students before breakfast, without clothes and after voiding, but presented the results as weight profiles only. Taggart ( 1962 ) carried out a careful study on one female subject: the change in body-weight from one day to the next ranged from $-0.8 \mathrm{r}$ to $+0.77 \mathrm{~kg}$ for the first experimental period of 80 days, but varied from -0.43 to $+0.3 \mathrm{I} \mathrm{kg}$ in the second period of 35 days when 'the food intake was kept constant and the activity as constant as was consistent with ordinary duties at work and at home'.

Daily weights have now been followed in women students living and eating in the same residential hall and attending similar courses at the university. The subjects were weighed each morning in a standard manner during the winter term. No 
attempt was made to control the extracurricular activities of the subjects, but these were recorded for assessing the effect of these activities on their daily weight. Because of the variations in the occurrence of menstruation, the results have been analysed in two parts. The present paper contains the day-to-day variations in weight observed throughout the whole study and the relationship of these variations to the menstrual cycle. The accompanying paper describes the changes in body-weight observed in the cycles completed during the experimental period which, in order to have two complete cycles, had to include three menses (Watson \& Robinson, 1965).

\section{EXPERIMENTAL}

Subjects. Daily measurements were made for 68 days during the winter term (from 30 May to 5 August 196r) on twenty-eight women students living in the same residential college, Studholme Hall. Ten were 18 years of age, seventeen were 19 , and one was 20. They attended either the and year degree or the and year diploma course of the Home Science School, University of Otago. None of the students intended to gain or lose weight, and none was undergoing any medical treatment.

Each student had a bed-sitting room kept at a comfortable temperature with central heating. No attempt was made to control or measure the food eaten or fluids drunk by the subjects. The three main meals were usually eaten in Studholme Hall where there was no choice of menu. The food eaten between meals varied considerably amongst the subjects.

Procedure. Each student was provided with her own clinical thermometer which was kept beside her bed. On waking she placed it in her mouth for $5 \mathrm{~min}$. She then rose and, after voiding her urine, dressed in brassiere and pants, and went to be weighed, taking her thermometer with her for her waking temperature to be recorded. Daily weighings took place each morning before breakfast between 7.1 5 and 8 am. On Sundays, subjects who did not attend early church services were weighed an hour later than on other days. At the time of weighing, the subjects reported for the previous day the absence or presence of menstruation, bowel activity and any illness or unusual activity such as examinations or dances.

Body-weight. All the subjects were weighed on an Avery beam balance capable of weighing up to $240 \mathrm{lb}$ and with a fine adjustment calibrated in oz. Reproducible results were obtained when the subjects stood in a standardized position on the platform. In a preliminary test of the accuracy of the weighing procedure, a subject who was weighed twenty-five times in one period of $15 \mathrm{~min}$, and then a further twentyfive times $30 \mathrm{~min}$ later, was found to have lost $\mathrm{I} \cdot 5 \mathrm{oz}$, which agrees in order of magnitude with the expected insensible loss of water. The weights have been converted into metric units and expressed in $\mathrm{kg}$.

Other measurements. Heights of the subjects without shoes were measured in in. The thicknesses of skinfolds over the triceps muscle, halfway down the left arm between the acromion and olecranon process, were measured with a Harpenden skinfold caliper (jaw pressure Io $\mathrm{g} / \mathrm{mm}^{2}$; rectangular jaw faces, $6 \times \mathrm{I}_{5} \mathrm{~mm}$ ). 
RESULTS

\section{General findings}

Table I contains the mean heights, weights (initial and final) and skinfold measurements of the twenty-eight subjects. There was a small average net gain in weight of $0.2 \mathrm{~kg}$ over the 68-day period of observation. The record for each subject was analysed for evidence of the presence of a linear trend and for those records in which the linear regression component was significant at the $5 \%$ level the form of this trend was determined and, to eliminate it, each observation was corrected accordingly. The daily weight changes of thirteen of the subjects showed a positive regression, of five subjects

Table I. Height, body-weight and skinfold thickness of twenty-eight young women

$\begin{array}{lrl} & \text { Mean and sD } & \text { Range } \\ \text { Height (in.) } & 65 \cdot 25 \pm 2 \cdot 25 & 62-69 \cdot 5 \\ \text { Initial weight }(\mathrm{kg}) & 61 \cdot 3 \mathrm{I} \pm 5 \cdot 83 & 5 \mathrm{I}-76 \\ \text { Final weight }(\mathrm{kg}) & 61 \cdot 52 \pm 5 \cdot 65 & 52-75 \\ \text { Weights corrected for trend } & & \\ \quad \text { Initial weight }(\mathrm{kg}) & 61 \cdot 47 \pm 5 \cdot 72 & 5 \mathrm{I}-76 \\ \quad \text { Final weight }(\mathrm{kg}) & 61 \cdot 35 \pm 5 \cdot 7 \mathrm{I} & 52-75 \\ \text { Skinfold thickness* }(\mathrm{mm}) & 21 \cdot 4 \pm 3^{\prime} \mathrm{I} & \mathbf{1 2 - 2 8}\end{array}$

* Measured over the left triceps muscle, half way between the acromion and olecranon process.

a negative regression, and those of the remaining ten subjects had no significant trend. The corrected weights have been used in all subsequent analyses and discussion of the results. The mean initial and final body-weights were little altered and became $6 \mathrm{r} \cdot 47 \mathrm{~kg}$ (SD $5 \cdot 72$ ) and $6 \mathrm{r} \cdot 35 \mathrm{~kg}$ (SD $5 \cdot 7 \mathrm{r}$ ). The average subject weighing $6 \mathrm{r}^{\circ} \cdot 47 \mathrm{~kg}$ was slightly overweight when compared with the height-weight figures of the Metropolitan Life Insurance Co., which give the desirable weight for women of 19 years with medium frame and height 67 in. (including 2 in. for shoes) as $118-\mathrm{r} 33 \mathrm{lb}$, which becomes $5 \mathrm{I} \cdot 3-58 \cdot \mathrm{I} \mathrm{kg}$ after correcting for $5 \mathrm{lb}$ clothing (Lew, 196I). That this difference in weight may not be due only to fat is suggested by the comparison of the values in Table $I$ with those for ninety-four women college students of mean age 20.4 years, whose mean height was similar (65.94 in., SD 2.3) (Young, Martin, Chihan, McCarthy, Manniello, Harmuth \& Fryer, 1961). The American students were a little lighter $\left(5^{8} .9 \mathrm{~kg}\right.$, range $44^{-76 \mathrm{~kg})}$ but had thicker skinfolds $\left(25^{\circ} .43 \mathrm{~mm}\right.$, sD 6.83), measured over the triceps muscle with a Lange skinfold caliper. This caliper has the same jaw pressure ( $10 \mathrm{~g} / \mathrm{mm}^{2}$ ) as the Harpenden caliper, but a smaller jaw face area, $25 \mathrm{~mm}^{2}$ in comparison with $90 \mathrm{~mm}^{2}$, respectively. The New Zealand students in this study may have had greater muscular development because of the active outdoor life to which they are accustomed.

The mean length of the menstrual cycle of $27^{\circ} \circ$ days ('Table 2 ) was not very different from the generally accepted length of 28 days. Menstruation lasted from 3 to 7 days. Whereas the dates of menstruation can be precisely recorded, those of ovulation are not so clearly defined. The presumed date of ovulation was estimated from the basal 
morning temperature graphs. These were almost complete records, for many of the subjects recorded their temperatures even when they were not weighed. In the graphs which showed a dip preceding the rise in temperature, ovulation was assumed to have occurred on the day on which the lowest temperature of the dip was recorded (Garcia $\&$ Rock, 1958). For the other graphs, the day of ovulation was taken as the last day before the temperature rose to a higher level which was maintained until the next menstrual flow (Marshall, 1963). The graphs of two cycles showed no distinct change in temperature and were designated as 'anovular'. Ovulation occurred 7-19 days before the onset of menstruation (Table 2).

Table 2. Length of menstrual cycle, of menstruation and of the time from
ovulation until onset of catamenia of twenty-eight young women

$\begin{array}{ccc}\text { Mean and SD } & \text { Range } \\ \text { (days) } & \text { (days) } \\ \text { Length of menstrual cycle } & 27 \cdot 0 \pm 5 & 15-42 \\ \text { Length of menstruation } & 5 \pm 1 & 3-7 \\ \text { Time from ovulation until } & 13.5 \pm 3 & 7-19 \\ \text { onset of catamenia } & & \end{array}$

Weights were missing for an average of 9 days per subject owing to weekend absences or being confined to bed (range 2-20 days). Seven of the students left the Hall for the 3 days of the Queen's birthday weekend which occurred 5 days after the experiment began. Although it was winter, very few subjects reported colds, sore throats or influenza. Only eight were too ill to be weighed and these just missed I day, except for one person who missed 2 days.

\section{Day-to-day changes in weight}

The day-to-day changes in body-weight were calculated for each subject throughout the study. On an average, fifty-two of the possible sixty-seven changes were obtained; no attempt was made to insert hypothetical figures when daily weighings were missed. The frequencies of fluctuations of different magnitude were calculated for each subject, and the results for a total of 1459 fluctuations in the twenty-eight subjects were combined together to give the frequency distribution illustrated in Fig. I. The range of variations was subdivided into intervals of $0.05 \mathrm{~kg}$, and each point plotted represents the number of observations within each interval. Vertical lines indicate variations of $\pm 0.5 \mathrm{~kg}$ and $\pm \mathrm{r} \cdot 0 \mathrm{~kg}$, respectively. The curve resembles that for a normal distribution: $50.2 \%$ of the variations were positive, $48.5 \%$ negative, and the remainder showed no change. Most of the fluctuations (86.6\%) lay within the range $\pm 0.5 \mathrm{~kg}$ and almost all $(98 \cdot 2 \%)$ within $\pm \mathbf{I} \cdot 0 \mathrm{~kg}$. Twenty-six variations exceeded $\mathrm{I} \cdot 0 \mathrm{~kg}$; of these $\mathrm{I} 2(0.8 \%)$ were negative and $\mathrm{I} 4(\mathrm{I} \cdot 0 \%)$ were positive. The maximum daily body-weight changes for each of the twenty-eight subjects varied from 0.59 to $2.07 \mathrm{~kg}$. In relation to body-weight the average maximum was $1.81 \%$, range 0.86 $3.67 \%$. For eleven of the subjects the maximum was within $1.5 \%$ of the body-weight, whereas of the other seventeen subjects, two had four day-to-day variations greater 
than $\mathrm{I} .5 \%$ of the body-weight, one had three, eight had two, and the remaining six subjects had only one. These outsize day-to-day variations, of which fifteen represented gains and eighteen losses in weight, were associated on seventeen occasions with changes in routine such as illness, extra bowel activity, feasting, or unusual exercise, and on the remaining sixteen occasions with nothing unusual at all.

The mean size of the day-to-day fluctuations was $0.279 \mathrm{~kg}$ (SD $0.240 \mathrm{~kg}$ ), equivalent to $0.46 \%$ of the initial body-weight (SD $0.08 \%$ ). The mean fluctuation was a daily increase of $0.005 \mathrm{~kg}$ (SD $0.367 \mathrm{~kg}$ ), indicating that the decreases had almost balanced

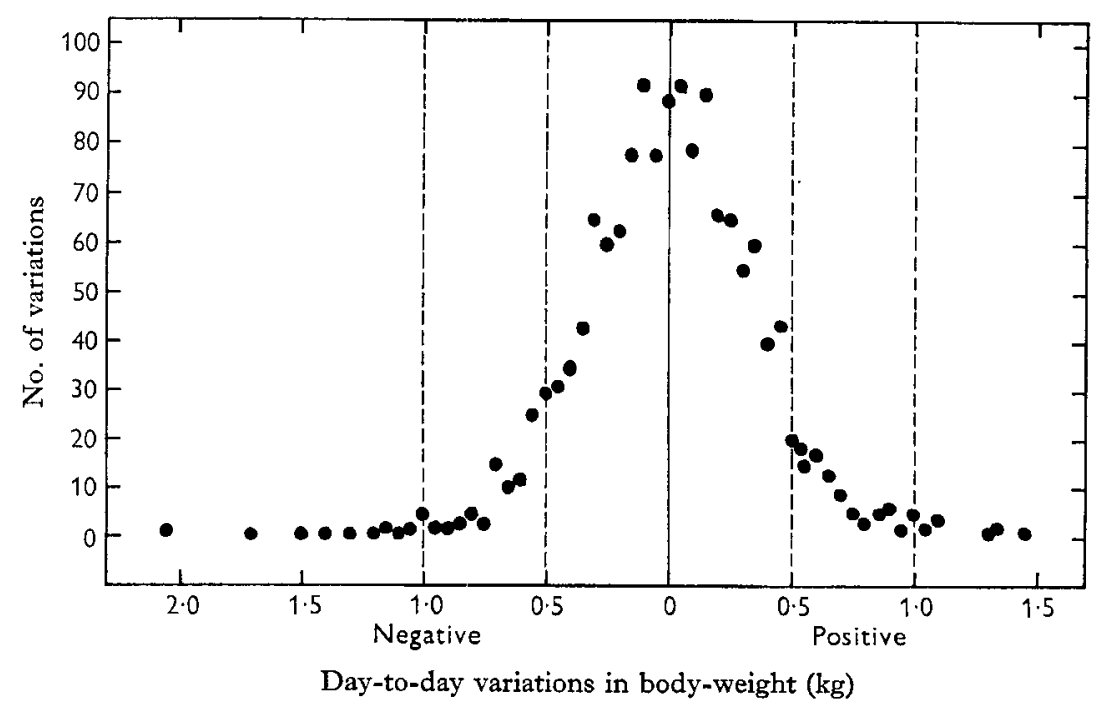

Fig. I. Frequency distribution of 1459 day-to-day variations in body-weight of twentyeight young women. Vertical lines (..-) have been drawn at $\pm 0.5 \mathrm{~kg}$ and at $\pm 1 \cdot 0 \mathrm{~kg}$, respectively.

out the increases. The mean change in body-weight, corrected for trend, was $-0.12 \mathrm{~kg}$. This is less than the mean effect of the day-to-day changes, $+0.26 \mathrm{~kg}(0.005 \mathrm{~kg} \times 52)$. The difference resulted from the change in body-weight of $-0.3^{8} \mathrm{~kg}$ associated with the gaps of one or more weighings. However these overall changes are not large in comparison with the mean size of the day-to-day change in body-weight.

\section{Effect of menstruation}

The $24 \mathrm{~h}$ interval ( $8 \mathrm{am}$ to $8 \mathrm{am}$ ) during which menstruation began is referred to as day $M$, days after $M$ being $M+I, M+2, \ldots$, and days before $M$ being $M-I$, $\mathrm{M}-2, \ldots$.

An analysis of the day-to-day fluctuations in weight throughout the cycle was made, and the results are summarized in Table 3. Fluctuations were tabulated from the beginning of the postovulatory phase (i.e. the day after ovulation was assumed to have occurred) through menses and the postmenstrual phase until the day ovulation occurred in the next cycle. Since ovulation took place between the $13^{\text {th }}$ and $\mathrm{r} 4^{\text {th }}$ days (average 13.5 days, range $7-19$ days) before the onset of menses and again between the 
$13^{\text {th }}$ and $14^{\text {th }}$ days (average $13^{\cdot 2}$ days, range $7^{-2} 3$ days) after menses began, fluctuations from day $M-I_{3}$ to day $M+I_{4}$ were considered. Table 3 contains the number of positive, negative and zero variations, together with the sums of the positive and of the negative variations, from which was calculated the mean fluctuation for each of the $24 \mathrm{~h}$ intervals taking account of the sign.

Table 3. Mean day-to-day variations, for twenty-eight young women, for each of the daily intervals about menstruation $(M)$, derived from the number of positive, negative, and zero day-to-day variations in body-weight, and the sums of the positive and negative variations

\begin{tabular}{|c|c|c|c|c|c|c|}
\hline 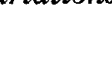 & & & & $\begin{array}{l}\text { Sum o } \\
\text { vari }\end{array}$ & $\begin{array}{l}\text { to-day } \\
\text { with }\end{array}$ & \\
\hline & No. of & o-day va & ns with & Positive & Negative & $\begin{array}{l}\text { Mean } \\
\text { dat-day }\end{array}$ \\
\hline Day & $\begin{array}{l}\text { Positive } \\
\text { change }\end{array}$ & $\begin{array}{l}\text { Zero } \\
\text { change }\end{array}$ & $\begin{array}{l}\text { Negative } \\
\text { change }\end{array}$ & $\begin{array}{l}\text { change } \\
(\mathrm{kg})\end{array}$ & $\begin{array}{c}\text { change } \\
(\mathrm{kg})\end{array}$ & $\begin{array}{l}\text { variation } \\
(\mathrm{g})\end{array}$ \\
\hline$M-13$ & 16 & - & 9 & $4 \cdot 16$ & $2 \cdot 28$ & +75 \\
\hline $\mathrm{M}-12$ & $x_{5}$ & - & 12 & 441 & 4.41 & \\
\hline$M-I I$ & 20 & - & I5 & 7.53 & 4.40 & +89 \\
\hline$M-10$ & 17 & I & 25 & 3.62 & 8.66 & $-I 17$ \\
\hline $\mathrm{M}-9$ & 20 & - & 20 & 6.70 & $4 \cdot 87$ & +46 \\
\hline $\mathbf{M}-8$ & 23 & - & I9 & $7 \cdot 62$ & $5 \cdot 34$ & +54 \\
\hline $\mathrm{M}-7$ & 21 & - & 22 & $3.6 \mathrm{I}$ & 7.90 & -100 \\
\hline$M-6$ & 30 & I & 12 & $9.0 \mathrm{I}$ & $2 \cdot 47$ & +152 \\
\hline$M-5$ & 18 & I & 27 & 472 & $8 \cdot 26$ & -77 \\
\hline$M-4$ & 26 & $x$ & 24 & $7 \cdot 32$ & 8.03 & -14 \\
\hline$M-3$ & 24 & - & 27 & $6 \cdot 29$ & $7 \cdot 15$ & -17 \\
\hline$M-2$ & 29 & - & 23 & $7 \cdot 55$ & $4 \cdot 15$ & +65 \\
\hline$M-I$ & 30 & 3 & $2 I$ & $7 \cdot 65$ & 5.43 & $+4 I$ \\
\hline $\mathrm{M}$ & 34 & - & 23 & 8.79 & 6.88 & +34 \\
\hline$\vec{M}+\mathbf{I}$ & 29 & 2 & 24 & 10.55 & $7 \cdot 21$ & $+6 I$ \\
\hline$M+2$ & 23 & - & $3 \mathrm{I}$ & 6.70 & $9 \cdot 73$ & -56 \\
\hline$M+3$ & 20 & $\mathbf{I}$ & 33 & 5.53 & $12 \cdot 02$ & -120 \\
\hline$M+4$ & 20 & - & 35 & $\begin{array}{l}5.18 \\
5.18\end{array}$ & 10.36 & -94 \\
\hline$M+5$ & 30 & $\mathbf{I}$ & 28 & $I I \cdot 2 I$ & $7 \cdot 39$ & +65 \\
\hline$M+6$ & 22 & - & 30 & 3.77 & $8 \cdot 35$ & -88 \\
\hline$M+7$ & 19 & 一 & 30 & 5.73 & 8.71 & $-6 I$ \\
\hline $\mathrm{M}+8$ & 35 & I & 15 & $9 \cdot 55$ & 3.99 & +109 \\
\hline$M+9$ & $\begin{array}{l}32 \\
25\end{array}$ & 2 & 17 & $7 \cdot 28$ & $\begin{array}{l}399 \\
4.58\end{array}$ & $\begin{array}{r}+6 r \\
\end{array}$ \\
\hline$M+$ ro & 17 & - & 22 & 3.86 & $7 \cdot 36$ & -90 \\
\hline $\mathbf{M}+\mathbf{I} \mathbf{I}$ & 20 & - & 21 & 6.52 & $5 \cdot 38$ & $\begin{array}{r}98 \\
+28\end{array}$ \\
\hline $\mathrm{M}+\mathrm{I} 2$ & 17 & - & 18 & $3 \cdot 83$ & 477 & $\begin{array}{l}-27 \\
-27\end{array}$ \\
\hline$M+I_{3}$ & 16 & - & I I & $4 \cdot 54$ & 3.60 & +35 \\
\hline $\mathbf{M}+\mathbf{I} 4$ & 9 & $\mathbf{r}$ & 12 & $2 \cdot 88$ & $2 \cdot 24$ & +29 \\
\hline
\end{tabular}

Because of the differences in the lengths of the menstrual cycles, in the times of ovulation, and also in the stages of the menstrual cycle reached by the subjects when the experiment began and finished, the numbers of variations from one day to another differed considerably. Since the commencement of menstruation was the starting point for this method of analysis, the greatest number of variations occurred at this time. Between forty-six and fifty-nine variations were recorded daily from $\mathrm{M}-5$ to $\mathrm{M}+5$, but before and after these, as ovulation was reached, the number of variations dwindled to as few as twenty-five for $M-I_{3}$, and to twenty-two for $M+I_{4}$. By this stage ovulation had occurred in half the cycles. A total of 1246 variations was in- 
cluded in this analysis; the remaining $2 \mathrm{I} 3$ variations had occurred outside the range of $M-I 3$ to $M+I_{4}$ inclusive, or else they had fallen during the postmenstrual or the premenstrual phase at the beginning or at the end of the study, respectively.

The values for the mean fluctuations together with their signs were used to derive
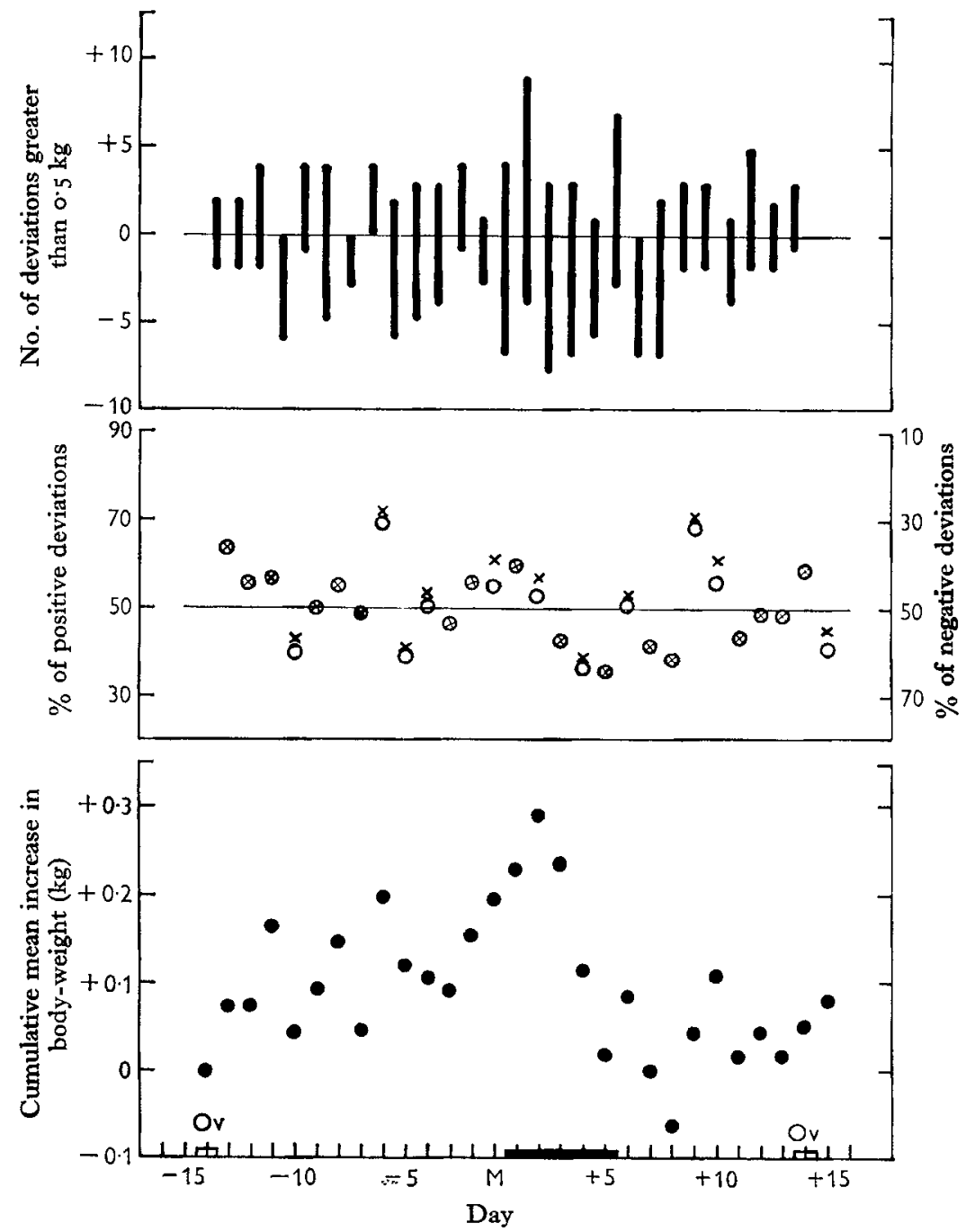

Fig. 2. Cumulative effect of the mean day-to-day variations in body-weight of twentyeight young women from day $\mathrm{M}-\mathrm{I}_{4}$ to day $\mathrm{M}+\mathrm{I} 5$ (see p. 229). Incidence of large day-to-day variations (greater than $0.5 \mathrm{~kg}$ ) plotted for each day, along with percentage of day-to-day variations which are positive $(O)$ or negative $(x)$; both symbols coincide $(\otimes)$ only when there are no zero deviations. Occurrence of menstruation (__ ) and ovulation (Ov) is shown on the abscissa.

the cumulative effect of the fluctuations from the $\mathrm{I}_{4}$ th day before until the $\mathrm{I}_{5}$ th day after menstruation began. The results are illustrated in the lowest part of Fig. 2. A cyclical pattern of weights emerged, indicating an increase in weight during the 
premenstrual phase to reach a maximum of $0.29 \mathrm{~kg}$ on the 2 nd day of menstruation. The weight then dropped during the remainder of menstruation to $0.06 \mathrm{~kg}$ below the initial value on the 8 th day after menstruation commenced, amounting to a fall in weight of $0.35 \mathrm{~kg}$. The initial weight was regained at the end of the postmenstrual phase.

The percentage of the day-to-day variations that were positive or negative is plotted for each period in the middle section of Fig. 2. About the time of menstruation, when most of the variations were recorded, there was a steady mean daily increase in weight of about $0.05 \mathrm{~kg}$ during the premenstrual phase, from the $3^{\mathrm{rd}}$ day before menstruation until the maximum weight was reached on the and menstrual day. This daily increase in weight might have been produced by the inclusion of many large positive fluctuations, but the incidence of day-to-day variations greater than $0.5 \mathrm{~kg}$ has also been included in Fig. 2, the positive ones above the horizontal axis, and the negative ones below it. It will be seen that while the weight was steadily increasing there was about the same number of large negative as of large positive fluctuations, and negative fluctuations preponderated on 3 of the 5 days. On day $M+I$ more large positive variations were found than at any other time, but large negative variations became more numerous with the fall in weight thereafter. The greater proportion of positive to negative variations obtained from day $M-3$ to day $M+r$ was also reversed. It would have been interesting to know whether these large changes in weight were caused by the retention or loss of fluids and whether menstruation had commenced with a small or large flow of blood during the first 2 days. No distinct pattern of weight change was apparent in the early premenstrual phase, or at the end of the postmenstrual phase.

Table 4. Mean day-to-day variations, for twenty-eight young women, for each of the daily intervals about ovulation $(\mathrm{Ov})$, derived from the number of positive, negative and zero day-to-day variations in body-weight, and the sums of the positive and negative variations

\begin{tabular}{|c|c|c|c|c|c|c|}
\hline & \multirow{2}{*}{\multicolumn{3}{|c|}{ No. of day-to-day variations with }} & \multicolumn{2}{|c|}{$\begin{array}{l}\text { Sum of day-to-day } \\
\text { variations with }\end{array}$} & \multirow{3}{*}{$\begin{array}{c}\text { Mean } \\
\text { day-to-day } \\
\text { variation } \\
(\mathrm{g})\end{array}$} \\
\hline & & & & \multirow{2}{*}{$\begin{array}{c}\text { Positive } \\
\text { change } \\
\text { (kg) }\end{array}$} & \multirow{2}{*}{$\begin{array}{c}\text { Negative } \\
\text { change } \\
\text { (kg) }\end{array}$} & \\
\hline Day & $\begin{array}{l}\text { Positive } \\
\text { change }\end{array}$ & $\begin{array}{l}\text { Zero } \\
\text { change }\end{array}$ & $\begin{array}{l}\text { Negative } \\
\text { change }\end{array}$ & & & \\
\hline $\mathrm{Ov}-4$ & 24 & - & 26 & $7 \cdot 4 I$ & $8 \cdot 16$ & -15 \\
\hline $\mathrm{Ov}-3$ & 34 & - & I4 & 13.60 & 3.51 & +222 \\
\hline $\mathrm{Ov}-2$ & 19 & - & 22 & 4.87 & $9 \cdot 02$ & $-I O I$ \\
\hline $\mathrm{OV}-\mathbf{I}$ & 25 & - & x9 & 5.60 & 5.87 & +6 \\
\hline $\mathrm{Ov}$ & 22 & - & $2 \mathrm{I}$ & $6 \cdot 60$ & $4 \cdot 48$ & +49 \\
\hline $\mathrm{OV}+\mathrm{I}$ & 30 & 2 & I7 & $8 \cdot 8 \mathrm{I}$ & 3.95 & $\begin{array}{r}+99 \\
\end{array}$ \\
\hline $\mathrm{Ov}+2$ & 29 & $\mathrm{I}$ & 23 & $7 \cdot 65$ & 5.59 & $\begin{array}{r}+39 \\
\end{array}$ \\
\hline $\mathrm{Ov}+3$ & 25 & 2 & 28 & $6 \cdot 14$ & $7 \cdot 64$ & -27 \\
\hline $\mathrm{Ov}+4$ & 25 & - & 22 & $6 \cdot 2 \mathrm{I}$ & $7 \cdot 44$ & -26 \\
\hline $\mathrm{Ov}+5^{*}$ & I6 & - & I 8 & $4 \cdot 45$ & $5 \cdot 27$ & -29 \\
\hline $\mathrm{Ov}+6 *$ & 16 & - & 22 & 443 & 5.09 & -39 \\
\hline $\mathrm{Ov}+7^{*}$ & 22 & - & 14 & 7.20 & 3.76 & $\begin{array}{r}597 \\
+107\end{array}$ \\
\hline
\end{tabular}

* Results for days $\mathrm{Ov}+5, \mathrm{Ov}+6, \mathrm{Ov}+7$ have been excluded for those subjects whose days $\mathrm{M}-5$ to $\mathrm{M}$ coincided with the period $\mathrm{Ov}+5$. 


\section{Effect of ovulation}

An analysis was carried out similar to the above but around the time of ovulation. Table 4 contains the number of variations, the sums of the positive and negative variations, and the mean day-to-day variation for the days from $\mathrm{Ov}-4$ to $\mathrm{Ov}+7$ where ' $\mathrm{Ov}$ ' was the $24 \mathrm{~h}$ interval during which ovulation was assumed to have taken

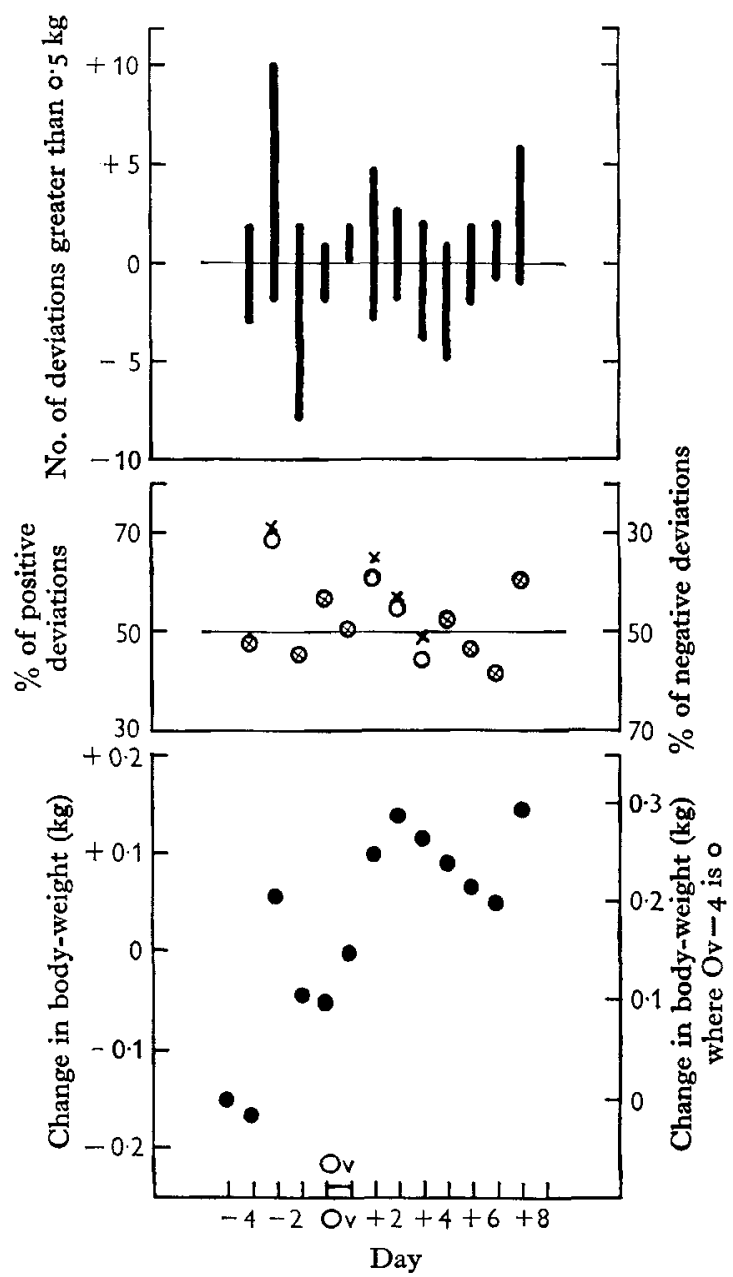

Fig. 3. Cumulative effect of the mean day-to-day variations in body-weight of twenty-eight young women from 4 th day before ovulation to 8 th day of postovulatory phase. (Left-hand scale: deviation of weight from time of ovulation as zero; right-hand scale: deviation of weight from day $\mathrm{Ov}-4$ as zero.) Incidence of large day-to-day variations (greater than $0.5 \mathrm{~kg}$ ) plotted for each day, along with percentage of day-to-day variations which are positive $(O)$ or negative $(x)$; both symbols coincide $(\otimes)$ where there are no zero deviations. Ovulation $(\mathrm{Ov})$ is shown on the abscissa. Day Ov+8 coincides with day $M-6$ in Fig. 2.

place. The cumulative weight change is illustrated in Fig. 3 along with the incidence of large variations and the percentage of positive and negative variations. This analysis could not have been extended beyond the days $\mathrm{Ov}-4$ and $\mathrm{Ov}+7$, without intruding 
upon the days of menstrual bleeding. Variations for days $\mathrm{Ov}+5$ to $\mathrm{Ov}+7$, inclusive, have been excluded from the analysis for the cycles in which day $\mathrm{M}-5$ coincided with day $\mathrm{Ov}+5$.

Many have reported an increase in weight at the time of ovulation, but this was not obtained on the day of ovulation in this study. A pronounced rise $(0.22 \mathrm{~kg})$ and fall $(0.10 \mathrm{~kg})$ in weight was shown on the $3^{\text {rd }}$ and the 2 nd day before ovulation, with corresponding changes in the incidence of large variations and in the percentage of positive and negative variations. Whether this rapid change in weight was the result of menstruation or was associated with impending ovulation is not known. The weight began to rise again during the supposed day of ovulation and reached its maximum value on the 2nd day of the postovulatory phase; thereafter it decreased gradually until the $7^{\text {th }}$ day, when it rose again sharply. These changes are demonstrated in the other graphs in Fig. 3. The last day in Fig. $3(\mathrm{Ov}+8)$ coincides on the average with day $M-6$ in Fig. 2, and so this sharp increase in weight may be the beginning of the premenstrual gain in weight found in the previous analysis of the variations about menstruation. In this study the maximum values reached (Figs. 2 and 3 ) occurred shortly after menstruation and ovulation, rather than coinciding with these events.

\section{DISCUSSION}

Khosla $\&$ Billewicz (1964) studied a number of groups mixed as to age and sex and concluded that under ordinary conditions day-to-day variations rarely exceeded $1.5 \%$ of the body-weight. Adam et al. (196r) found day-to-day changes greater than $0.5 \mathrm{~kg}$ in $30 \%$ and over I $\mathrm{kg}$ in $6 \%$ of 1700 weighings of sixty-four soldiers. Our female subjects were less numerous than the soldiers but they were observed over a longer period and their conditions of life were at least as rigidly controlled. The women restricted their social activities to the weekends and studied most evenings during the week. Our day-to-day variations were smaller than those of the soldiers and the overall picture exhibited a cyclical pattern in time with the menstrual rhythm. This relationship was not present in all the cycles (Watson \& Robinson, 1965), and indeed Khosla \& Billewicz (1964) found no consistent effect on weight in seven menstrual cycles.

If, as seems likely, the day-to-day fluctuations were primarily due to alterations in body water, the fact that they tended to be smaller in our subjects than in the soldiers may have been related to the fact that the bodies of the young men were likely to have contained more water and less fat.

\section{S UMMARY}

r. Daily weights have been followed for 68 days in twenty-eight young women students (aged $18-20$ years) living and eating in the same residential hall and attending similar courses at the University. Each morning on rising the students were weighed in a standardized manner. Basal morning temperatures were recorded.

2. Day-to-day changes in body-weight showed an almost normal distribution; $13.4 \%$ were greater than $0.5 \mathrm{~kg}$, and $\mathrm{I} .8 \%$ greater than $\mathrm{I} \cdot 0 \mathrm{~kg}$.

3. Cumulative effects of the mean day-to-day variations for each day of the men- 
strual cycle led to an increase in weight during the premenstrual phase, reaching a maximum value on the and day of menstruation, followed by a clear downward trend until the 8th day after the onset of menstruation.

4. There was also a minor peak in body-weight 2 days after the date of ovulation indicated by the basal morning temperatures.

We wish to thank the subjects, without whose friendly co-operation this study would have been impossible. We are indebted to Mr G. F. Spears, Statistician, Department of Preventive and Social Medicine, Medical School, for his advice and for the compensating corrections required in the records of those subjects who gained or lost weight, and to Professor J. R. Robinson, Department of Physiology, Otago University Medical School for his helpful suggestions and interest in this study.

\section{REFERENCES}

Adam, J. M., Best, T. W. \& Edholm, O. G. (196r). 7. Physiol. 156, $38 P$.

Chesley, L. C. \& Hellman, L. M. (1957). Amer. F. Obstet. Gynec. 74, 582.

Danforth, D. N., Boyer, P. K. \& Graff, S. (1946). Endocrinology, 39, 188.

Durnin, J. V. G. A. (196r). Proc. Nutr. Soc. 20, 52.

Edholm, O. G. (r96r). Proc. Nutr. Soc. 20, 7 r.

Fortin, J. N., Whittkower, E. D. \& Kalz, F. (1958). Canad. med. Ass. Y. 79, 978.

Garcia, G. R. \& Rock, J. (1958). In Essentials of Human Reproduction, p. 34. [J. T. Velardo, editor.] London: Oxford University Press.

Khosla, T. \& Billewicz, W. Z. (1964). Brit. F. Nutr. 18, 227.

Klein, L. \& Carey, J. (1957). Amer. F. Obstet. Gynec. 74, 956.

Lew, E. A. (1961). F. Amer. diet. Ass. 38, 323.

Marshall, J. (1963). Brit. med. F. i, 102.

Taggart, N. (1962). Brit. F. Nutr. 16, 223.

Thomas, C. B. (1953). Ann. intern. Med. 39, 289.

Watson, P. E. \& Robinson, M. F. (1965). Brit. \%. Nutr. 19, 237.

Young, C. M., Martin, M. E. K., Chihan, M., McCarthy, M., Manniello, M. J., Harmuth, E. H. \& Fryer, J. H. (196r). F. Amer. diet. Ass. 38, 332. 